\title{
Article
}

\section{The initiation of labour at term gestation: physiology and practice implications}

\author{
Hundley, Vanora, Downe, Soo and Buckley, Sarah J. \\ Available at http://clok.uclan.ac.uk/31796/ \\ Hundley, Vanora, Downe, Soo ORCID: 0000-0003-2848-2550 and Buckley, \\ Sarah J. (2020) The initiation of labour at term gestation: physiology and \\ practice implications. Best Practice \& Research Clinical Obstetrics \& \\ Gynaecology, 67 . pp. 4-18. ISSN 1521-6934
}

It is advisable to refer to the publisher's version if you intend to cite from the work. http://dx.doi.org/10.1016/j.bpobgyn.2020.02.006

For more information about UCLan's research in this area go to http://www.uclan.ac.uk/researchgroups/ and search for <name of research Group>.

For information about Research generally at UCLan please go to http://www.uclan.ac.uk/research/

All outputs in CLoK are protected by Intellectual Property Rights law, including Copyright law. Copyright, IPR and Moral Rights for the works on this site are retained by the individual authors and/or other copyright owners. Terms and conditions for use of this material are defined in the policies page.

\section{CLoK}

Central Lancashire online Knowledge www.clok.uclan.ac.uk

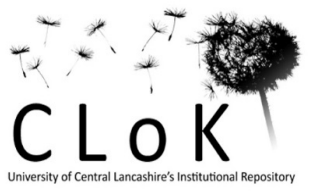


The initiation of labour at term gestation: physiology and practice implications

Vanora Hundley ${ }^{\mathrm{a}}$, Soo Downe ${ }^{\mathrm{b}}$, and Sarah J Buckley ${ }^{\mathrm{c}}$

a. Centre for Midwifery, Maternal \& Perinatal Health, Bournemouth University, Christchurch Road, Bournemouth, BH1 3LT, United Kingdom. Email: vhundley@bournemouth.ac.uk

b. School of Community Health and Midwifery, University of Central Lancashire, Brook Building, Preston, PR1 2HE, United Kingdom. Email: sdowne@uclan.ac.uk

c. School of Public Health, The University of Queensland, 288 Herston Rd, Herston, QLD 4006, Australia. Email: drsarahjbuckley@gmail.com

Corresponding author:

Vanora Hundley

Professor of Midwifery,

Centre for Midwifery, Maternal \& Perinatal Health,

Bournemouth University,

Christchurch Road,

Bournemouth, BH1 3LT,

United Kingdom

Email: vhundley@bournemouth.ac.uk 


\section{Abstract}

Little is known about the physiology of labour onset at term, and there is a debate about what signs and symptoms should be used to define it. In low resource settings and, particularly, for remote and rural communities, delay in recognising labour onset may mean a delay in seeking a skilled birth attendant. This chapter presents the most recent evidence about the physiology of labour onset, including the complex neuro-hormonal, biophysical, psychological and emotional factors that contribute. The symptoms of labour onset are explored from the perspective of both pregnant women and service providers in a range of sociocultural contexts. Early labour presents challenges for pregnant women, their families, communities and health care professionals. The chapter discusses how maternity care services should be designed, and delivered to ensure that women get the optimum advice and care at the beginning of labour.

\section{Highlights}

- Complex neuro-hormonal, biophysical \& psychological factors contribute to labor onset

- There is debate about what signs and symptoms should be used to define labor onset

- Early labour presents challenges for pregnant women and health care professionals

- Hospital admission before active labor leads to a cascade of unnecessary intervention

- Optimal maternity care requires understanding of women's experiences of early labor

\section{Keywords}

Labor Onset, Labor physiology, Labor experiences 


\section{Introduction}

Initiation of labour is variously defined and interpreted. Almost a century ago, in the 1931 edition of a text book for obstetricians (titled 'Midwifery by Ten Teachers'), Berkeley et al noted 'Why labour comes on at the end of forty weeks gestation is unknown' [1]. The authors dismissed the then current labour onset theories of menstrual length, uterine distention, and placental infarction. Instead, they hypothesised that 'The most likely explanation is that some substance is produced in the ripe placenta which excites the labour-centre in the cord' [1].

Eighty years later, despite the extensive subsequent research, Kamel was forced to conclude that 'the mechanism by which labour is initiated in humans remains obscure' [2]. This situation has not changed. Evidence to date tends to suggest that the triggers may include inflammatory, hormonal, and mechanical factors. It is not clear how far these are imitated by fetal or maternal processes. There may also be relevant psychosocial effects via the maternal immune system or other mechanisms, though this has not been widely researched to date.

Because little is known about the physiology of labour onset at term, there is a debate about what signs and symptoms should be used to define it $[3,4,5]$. This raises questions for women and providers about when they should seek maternity care, and about the kind of care that should be made available if women present when they are not in labour. It is particularly important to make the right judgement about labour onset when women do not have rapid or easy access to maternity care, for geographical, costs, or other reasons. The lack of clarity and agreement in this area also influences the implications and appropriate application of research studies in which length of labour is an outcome.

In low resource settings and, particularly, for remote and rural communities, delay in recognising labour onset may mean a delay in seeking a skilled birth attendant (SBA). Lack of access to SBA support is associated with a higher risk of maternal and neonatal morbidity and mortality [6]. Missing the signs of labour onset may also mean a delay in setting off for the local maternity facility, if that is the intended place of birth, or a delay in calling on local skilled birth attendants, if the birth is planned to take place at or near the woman's home [7]. However, the risk of late access need to be balanced by the implications of early hospital admission (before active labour), including the associated 'cascade of unnecessary interventions', typically seen in both high resource [8-13] and low resource settings $[14,15]$. 
Rates of routine induction of labour for uncomplicated postmaturity are rising in many settings [16]. In addition, there are recent calls for routine induction of labour at 39 weeks gestation for healthy, low-risk women, to reduce rates of caesarean section [17] and/or stillbirth [18]. Lack of understanding about the finely tuned anatomical, biochemical and neurohormonal processes that trigger labour onset may lead to an underestimate of the short and longer term neurohormonal impacts of labour induction, particularly where this is done routinely in the early term period (37 0/7 weeks to $386 / 7$ weeks).

In some cases, women with term pregnancies attempt to start the labour process themselves. To be able to provide the best care possible in these cases, it is important for maternity care providers to understand why women are trying to initiate their own labour, and the techniques and substances they may use.

This chapter aims to present the most recent evidence in this area, and the implications for clinical practice. The first section addresses what is known about the physiology of labour onset. The second section explores varying interpretations of the symptoms of labour onset, from the perspective of both pregnant women and service providers in a range of sociocultural contexts. We then consider the implications of these varying views, experiences and interpretations in terms of the information about labour onset that should be provided for pregnant women, their families and communities, and about how maternity care services should be designed, and delivered to ensure that women get the optimum advice and care at the beginning of labour. Finally, we suggest new areas for research to address some of the continuing debates and controversies in this area.

\section{Current evidence on the physiology of spontaneous labour onset}

Since the hypothesis of Berkeley et al [1], advances in knowledge have revealed that mammalian biological processes are not simple linear functions. Biological systems involve dynamic complex processes that can facilitate adaptations to internal and external changes. This is equally true of childbirth, where evolution has resulted in complex, exquisitely balanced, multi-system processes for labour onset that are likely to include psychological factors and adaptations [19]. Evolutionary considerations suggest that the expectant female's subjective feelings of safety versus stress and danger could be important contributing factors to labour onset, as giving birth in an unsafe environment would risk the survival of mother and offspring.

Survival at birth also requires that both mother and baby are well prepared for the stresses of labour and birth, and for the biologically extraordinary post-birth transitions. There are dynamic 
interactions between mother and baby to coordinate the timing of labour onset, including the completion of necessary physiologic pre-labour preparations $[19,20]$. The result is that spontaneous labour onset at term in healthy pregnant women usually occurs when both mother and baby are at peak biological, neurohormonal, and psychological readiness for labour, birth and successful postpartum / neonatal transitions.

To ensure this optimal timing, changes in the mother and the fetus towards the end of pregnancy begin to shift the uterus from its quiescent (phase 0 ) to activation (phase 1), ensuring optimum conditions for stimulation (phase 2) and involution (phase 3), [21] as illustrated in Figure 1.

\section{\{Figure 1 here\}}

\subsection{Physiology of the uterus at labour onset}

Throughout gestation, mother and fetus communicate with each other via the placenta. This communication includes the placental production, metabolism and/or distribution of hormones and other factors as described in this section. In the lead-up to labour, these placental processes ensure that activation of the mother's uterus happens in parallel with maturation of fetal organs.

Towards the end of pregnancy, the developing fetal adrenal glands produce increasing amounts of cortisol. This steroid acts to mature fetal organ systems, especially the lungs. The maturing fetal adrenal also produces increasing amounts of dehydroepiandrosterone (DHEA), which is an important precursor for oestrogen production in the placenta. Oestriol, the dominant oestrogen in pregnancy, then enters the mother's circulation and triggers the uterine activation phase in readiness for labour.

Oestrogen effects include:

\section{- An increase in uterine gap junctions}

Gap junctions are intercellular connections that enhance the spread of electrical signals. This essentially 'wires up' the uterus for effective coordinated contractions in labour. Under the influence of oestrogen and prostaglandins, gap junctions increase substantially up to labour onset.

- Uterine oxytocin receptors 
The uterotonic effects of oxytocin in labour depend on uterine sensitivity, which is determined by the number and activity of uterine oxytocin receptors. Uterine oxytocin receptor numbers rise around twelve-fold from mid pregnancy to term, and are even higher in early labour [22], so that only small amounts of circulating oxytocin are required to initiate and maintain labour (equivalent to 4-9 $\mathrm{mU} / \mathrm{min}$ ) [23]. In addition, strong, oxytocin-fuelled contractions drive a positive feedback cycle, whereby uterine sensations trigger oxytocin release from the maternal brain, causing stronger contractions and more oxytocin release.

This has implications for labour induction, which is unlikely to succeed if the individual woman undergoing induction is not yet far enough into her pregnancy to have developed adequate uterine oxytocin receptor numbers to ensure optimum uterine sensitivity [24]. In addition, the increase in uterine oxytocin receptors occurs in parallel with other activating processes, described below. These may be equally necessary for an effective labour and birth.

\subsection{Other physiological processes}

Reduction in quiescence

The shift to activation also involves reductions in the factors that have previously supported quiescence. These could include down-regulation in the effects of progesterone, the major progestation hormone. However, the relevant functional mechanism is not fully understood, as circulating levels of progesterone do not decline before labour onset [21].

Prostaglandins and inflammation

Recent research has highlighted the occurrence of a sterile inflammation in local fetal and maternal tissues, even before labour onset [25]. Pro-inflammatory chemicals, including cytokines and interleukins, promote the production of prostaglandins, which help with collagen degradation and cervical ripening. Prostaglandins in the uterus promote contractility by increasing oxytocin receptors and gap junctions and also increase placental production of the activating hormone Corticotropin Releasing Hormone ( $\mathrm{CRH})$, fuelling additional positive feedback cycles [25].

The fetal membranes and amniotic fluid may also mediate signals between the mother and baby [25]. The maturing fetal lungs secrete surfactants into amniotic fluid, which may promote local prostaglandin production and uterine contractility [25]. Loosening of the tissue interface ('glue') 
between the fetal membranes and the uterine wall results in raised levels of fetal fibronectin in the week or so prior to labour onset.

\subsection{Corticotrophin Releasing Hormones (CRH): the 'placental clock'}

Outside of pregnancy, $\mathrm{CRH}$ is a high-order stress hormone produced in the hypothalamus, which triggers the release of adrenocorticotropic hormone (ACTH) from the pituitary, and subsequently cortisol from the adrenal gland. In pregnancy, large amounts of CRH are made by the placenta, with uterine activating effects in the lead-up to labour by several mechanisms. These include: stimulation of fetal DHEA and subsequent placental oestrogen production; promotion of inflammation; and direct pro-contractile effects [21]. Placental CRH also reaches the baby, promoting cortisol production and organ maturation. Above-normal CRH levels in mid-pregnancy have been associated with an increased risk of preterm birth, suggesting that the 'placental clock' may be set too early in some women. Both $\mathrm{CRH}$ and prostaglandins are also involved in positive feedback loops that drive labour [21].

\subsection{Impact of late pregnancy/labour initiation priming on the fetus/neonate}

In addition to these fetal pre-labour preparations, the processes of physiological labour and birth further optimise the fetal-to-newborn transition. The so-called 'stress of being born' involves a latelabour surge of adrenaline and noradrenalin, which maximises newborn adaptations, including the critical respiratory transition, as shown in figure 2 . This fetal catecholamine surge is facilitated by the prelabour upregulation in adreno-receptors in these fetal organ systems $[26,27]$.

\{Figure 2 here\}

All of the factors listed above are part of a dynamic, integrated, multisystem interaction between mother and fetus, which come together in a finely balanced synergy to prime the mother/fetal dyad for optimal labour and birth. Additionally, there are significant benefits in waiting for spontaneous labour onset for the healthy neonate $[28,29]$ since the fetal brain continues to grow and develop up to the moment of birth.

\section{Imminent labour onset and early labour: signs, symptoms and triggers}

\subsection{Behaviours reported by women}


In a range of mammalian species, specific pre-labour signs have been observed, including restlessness [30,31] and a drop in temperature about 24 hours before labour onset [32-34]. However, this area is not well studied in humans.

An in-depth qualitative study of $18 \mathrm{New}$ Zealand women reported that most women experienced excitement when they believed their labour had started, as well as some apprehension and anxiety [35]. One of the respondents made reference to anecdotal reports of an increase in energy just before labour onset, associated with an urge to tidy up and prepare the house for the coming baby. This behaviour, termed 'nesting' behaviour [36,37], is well accepted for other mammals, including pigs [38] and rabbits [39]. However, nesting has not been extensively examined in humans.

In one of the few reports in this area, Anderson and Rutherford report on two psychological studies that developed and tested a psychometric 'nesting' scale, including a total of 375 women, in which human nesting was defined as 'measurable change in behaviours and attitudes related to birth preparation that happens during pregnancy' [36]. Associated behaviours were conceptualised broadly as either space preparation (unusually intensive cleaning and organising of the home environment), and social selectivity (choosing to spend more time with people who were more highly trusted or familiar).

The first study reported in the Anderson and Rutherford paper [36] compared behavioural reports from pregnant and non-pregnant women, and the second followed pregnant women longitudinally. The findings demonstrated that, for the included respondents, there was an increase in nesting behaviours from the first to the third trimester, and in comparison to non-pregnant women. The authors comment that the type of behaviours noted towards the end of the third trimester included: a focus on home renovations and completion of projects, an energy burst, and the purging and sorting of household items. Ridding the environment of unwanted items is prioritized as highly as organizing the items that will remain after the baby is born. Compared to non-pregnant women, women in late pregnancy showed a preference for being close to home, a strong preference for kin and close friends, and report that new people and places are relatively unappealing. The data for both Anderson and Rutherford studies were collected in Canada from participants recruited via social media [36]. It isn't clear how far these experiences and behaviours are evident across cultures, or how precisely they can be linked to imminent labour onset.

\subsection{Physical signs and symptoms of labour onset}


In terms of physical signs and symptoms, women experience the initiation of labour in a variety of ways, including pain (usually back pain), watery or blood-stained loss, gastrointestinal symptoms, emotional changes and altered sleep patterns $[35,40,41]$. Most women can identify approximately when their labour started, and the literature suggests that they usually experience it as a continuous process of increasing intensity $[35,40]$. In contrast, health care providers tend to focus on the somewhat arbitrary phases of labour defined by Friedman and Kroll, who described labour as being latent (from onset of labour to degree of cervical dilatation after which the rate of dilatation significantly increases, which was originally classified as $2.5 \mathrm{~cm}$ ) or active (from the point in time at which the rate of change of cervical dilatation significantly increases to the approximate onset of second, expulsive, stage) [42]. This division has gained importance because of the move to hospital birth [43], and the impact on women of admission to hospital in latent labour [4]. There is strong evidence that women admitted to hospital in the latent phase of labour are more likely to experience a cascade of unnecessary intervention that increases the risk of both maternal and neonatal morbidity [8-15].

\subsection{Triggers for labour onset noted by women}

Bovbjerg et al undertook a secondary analysis of data from 663 women who participated in the USA Third Pregnancy, Infection, and Nutrition cohort and who did not have a clinical induction of labour [44]. Sixty percent reported no specific triggers for labour onset. For the $40 \%$ who believed there was a specific cause, 49 different triggers were recorded in a free-text response box. The group of activities noted by the largest number of respondents was categorised as physical activity or other physical triggers ( $n=87$ ), including formal exercise, such as swimming or walking, non-formal activity such as housework, sexual activity, or 'baby did something'. Apart from a 'clinician induced' set of activities ( $n=65)$, the next most prevalent group was coded as 'natural phenomena' ( $n=52)$, and included cramping, a bloody show, or rupture of membranes. Other categories were maternal illness, ingesting something, and emotional triggers.

There appear to be no similar studies of women's accounts of labour triggers from low or middle resource settings.

\section{Techniques women use to stimulate labour onset}

Around the world, some women in late pregnancy use techniques to initiate labour if they feel their pregnancy has gone on too long. The prevalence of this phenomenon is hard to quantify, though in 
one specific (US) setting it has been reported to be $22 \%$ of pregnant women [45]. The decision to initiate labour may be made because women are anxious about the wellbeing of the baby and/or themselves, for financial, social, or personal reasons, or to avoid scheduled clinical induction for postmaturity. Often health care providers will not know that women have stimulated labour onset, but it is important to be aware of the reasons why this may be done, and of the rare but sometimes critical side effects. From a primarily US perspective, Bovbjerg et al note that:

rumors of "conventional" ways of inducing labor abound in the popular literature and include nipple stimulation, acupuncture, acupressure, massage, sexual intercourse, raspberry leaf tea, spicy food, balsamic vinegar, walking, castor or cod liver oil, enema, black or blue cohosh, heavy exertion, dehydration, starvation, stress, fear, and mechanical agitation such as riding in a car along a bumpy road [44]

By 'conventional' they mean 'not clinical'. Similar means of self-initiating labour have been reported in a number of settings [46-48]. Some herbal preparations that are used to initiate labour are associated with case reports of harm [49]. This includes blue cohosh, which has been associated with acute cardiac episodes [50]. There are reports of maternal use of herbs in pregnancy in an African context, with warnings about potential severe side effects, including postnatal bleeding, but these do not appear to be primarily employed to self-initiate labour [51]. Peprah et al report the use ginger, peppermint, thyme, chamomile, aniseeds, green tea, tealeaf, raspberry, and echinacea leaf in rural Ghana, for a range of reasons [52], and these and other preparations are reported in other African studies of remedies used in pregnancy to aid labour though not specifically for labour initiation [48]. Participants in Peprah et al's study also had a strong belief in herbal remedies and a parallel conviction that most clinical medication was ineffective [52]. The authors reported that some participants would not tell their health care provider that they were using herbal remedies during pregnancy.

Kamatenesi-Mugisha and Oryem-Origa reported the use of over 75 different herbal plants to induce labour in Uganda, some of which are reported to have oxytocic properties [53]. The authors warn that some of the plants listed could have adverse effects on the mother and/or baby, though these specific plants, and the events that they are associated with, are not reported in the paper.

In contrast, in a recent systematic review of non-pharmacological remedies to induce labour only two substances identified as being used regularly for this purpose (raspberry leaf tea and castor oil) 
[47]. This review of ten papers focused only on high income countries. No evidence of harm was reported, though the authors note the paucity of evidence in this area.

\section{Recognition and diagnosis of labour onset, and consequences for access to care provision}

For all women and staff, recognition of the onset of labour is important to ensure the best support and care for the mother and baby. Where access to labour care is difficult for financial or geographical reasons, it is particularly important for women to be able to identify labour onset accurately. In some settings, it is usual to wait until labour is felt to be established before accessing any external support, or beginning to move to a facility. However, where women live very far from the place they intend to give birth, or where there are few local care providers, women need to be able to convince other family or community stakeholders that they are in early labour, in order to be able enlist their help and (financial or other) support to access maternity care, either locally, or at a distance. This may take time, so contact with such stakeholders needs to happen as early as possible in the labour process.

\subsection{Tests for the diagnosis of labour onset}

At present, there are no definitive diagnostic tests for labour onset. The diagnosis can only be made retrospectively, once labour is established. Although tests such as the evaluation of the presence of fetal fibronectin have been proposed, there is little evidence of its efficacy for routine use for women with term pregnancies [54]. Recent studies have focused on pro-imflammatory factors, including telomere loss and increased cell-free fetal DNA (cffDNA) levels [55]. However, to date, no tests have high specificity and sensitivity for labour onset at term, and they are expensive for use in a low resource context. It is of interest that the observations noted above about a drop in temperature in horses, dogs and sheep within 24 hours of labour onset do not seem to have been followed up in humans, given the potential simplicity and inexpensiveness of such a measure if it is found to be a reliable indicator.

Even if there were highly accurate tests, the issue of what to do for women who have travelled a long way to a facility, and are then subsequently found not to be in labour, remains. In the absence of a definitive test, maternity care providers should pay close attention to women's accounts of what they are experiencing, and of what they believe this means for them and their labour. Even if what women say does not fit with the 'standard' account of labour onset used by local health care providers, it could still be a good indicator of labour onset in a particular woman, especially if she 
has experience of labour onset from previous pregnancies. The decision about whether to provide her with labour support includes listening to her emotional and social reasons for wanting to enter a maternity unit and/or to be visited by a skilled birth attendant.

\subsection{Labour onset cues used by women and health care providers}

The success or otherwise of women's attempts to access skilled support in labour depends on the extent to which their accounts of being in labour are believed by gatekeepers of maternity care. The messages and cues about labour onset that health care providers hear from a woman help them to decide whether or not she is likely to need skilled labour care (in a facility or in the community) in the near future. A mismatch between the way women experience and report labour onset and the way that health care providers expect it to be experienced and reported risks delaying a correct diagnosis and may lead to inaccurate decision making.

There appear to be no studies of the views, experiences and beliefs of health care providers with medical backgrounds in terms of what initiates labour, or of signs and symptoms related to this process $[3,4,5]$. However, research undertaken with midwives indicates that health care providers use a range of cues in deciding whether a woman should be formally acknowledged to be in active or established labour $[56,57]$. These include signs relating to the woman (physical symptoms, distress and coping, expectations, and social factors), but also conditions relating to the institution (organisational factors, midwifery care and justifying actions) [56,57]. These were summarised pictorially by Cheyne et al [56], see Figure 3 below.

\{Figure 3 here\}

While there are similarities between the labour onset cues reported by women $[40,41,44]$ and those reported by health care providers [56,57], there are also some differences. These differences can be the source of friction. For example, there is some evidence to suggest that women perceive health care providers to be the gatekeepers to hospital care because they have the ability to define active labour [58]. The result is an 'asymmetric power relationship' [59], whereby the woman must determine the right time to seek hospital admission or risk being sent home 'not in labour' [60]. However, this confidence in professional knowledge could well be misplaced. Defining labour onset is a cause of considerable uncertainty among midwives and other health care providers $[3,4,57,61]$ and clinicians frequently have difficulty distinguishing between the phases of labour [62]. In 
addition, the process has been described as cyclical and dynamic in nature, rather than something achieved through a one off assessment [57].

A mismatch between women's and health care providers' perceptions of labour onset can result in significant discomfort and/or distress for both parties. For women there is the uncertainty regarding when to seek care and support. Women must balance a need to know how 'far along' in labour they are, risking arriving too early, with the fear that they might give birth on route to hospital $[59,63,64]$. Arriving too early and being sent away makes women feel that their labour experience is not valued $[60,65,66]$ and, although health care providers may see this as protecting women from unnecessary interventions, it is not a person-centred approach to care [67]. Terminology such as 'false diagnosis' of labour further disempowers women [68].

In all cases, if the woman's account of her labour is dismissed or even ridiculed by health care providers, there are potentially serious implications for the quality of maternity care. This includes her emotional and psychological wellbeing and, in extreme cases, the physical safety of mother and/or baby may be at risk if the mother is turned away and does not return. The implications of disrespectful care are further considered in chapter 12 of this volume [69].

Health care providers feel equally uncomfortable and constrained by existing services $[56,70]$. They recognise a need to support women in latent phase labour, while at the same time protecting them from the potential use of unnecessary interventions associated with hospital admission. The balance is particularly acute in low resource settings where women have travelled a long distance to access care [14].

\section{Potential new approaches to recognition, diagnosis and management of labour onset}

Information from local women's accounts of labour onset could be integrated into communityspecific information leaflets and advice provided by SBA and others such as Traditional Birth Attendants (TBA) and Accredited Social Health Activists (ASHA). Many local beliefs about the signs and symptoms of labour onset have developed based on years of experiential knowledge. Given how little is known scientifically in this area, it would be sensible to pay attention to experiential knowledge, especially when it is biologically plausible. 
New solutions might include solar powered mobile devices that have video capacity, and that are made available in rural and remote communities to enable pregnant women to make rapid remote contact with care providers. The link could either be to local SBAs or to more remote facilities if that is where women are intending to give birth. Studies from high resource countries suggest that home visits to establish if women are in labour do not significantly improve diagnosis or women's experiences [71]. Telephone contact between pregnant women who think they are in labour and midwives based in a local facility has been explored [72]. There were mixed results, which appeared to depend on whether the midwives concerned saw this as a way to keep women out of hospital as long as possible, or whether they saw the telephone contact as a way of personalising care, advice, and hospital entry to the needs and expectations of the individual woman. The authors concluded that telephone contact with women in relation to early labour should be undertaken by health care providers dedicated to this task. A recent review of studies of telephone triage for a range of situations in maternity care concludes that there is not enough primary research in this area to reach a firm conclusion about its benefits or disadvantages [73]. The authors note that the findings are in line with previous research $[56,72]$, which indicated that negotiating with women about facility entry in early labour is a complex process in which midwives have to balance the needs of the woman, and moment-to-moment changes in labour ward conditions.

One of the problems in this area is that women who are told they are not in labour find it hard to determine when that situation has changed, and when they should either re-visit a facility to try to seek entry, or when they should phone back health care providers who they know are busy [64]. In Papua New Guinea mobile phones and a free-call emergency number (the 'maternal health phone line') are being used to overcome the communication issues associated with delay in seeking care in labour [74]. There is evidence that mHealth interventions targeted at pregnant women can increase service utilisation [75], but no studies have looked at the impact in relation to early labour care. Future research could assess the effects of regular mobile phone contact between SBAs and women who think they might be in early labour as a basis for optimum decision making about transportation or skilled birth provider attendance. Given women's reluctance to call a busy facility, if an earlier call has resulted in advice to stay at home, such research should enable health care providers to initiate regular follow up calls until the woman is finally admitted in labour. Other solutions include the placement of the phone line. In some maternity service in the UK, the 24 hour 'labour line' has been moved from the maternity ward to an ambulance control centre. Calls are triaged by a dedicated midwife enabling women to receive support and advice [76]. 
For those who live too remotely to travel in early labour, but who are willing and able to move closer to facilities in late pregnancy, maternity homes or hotels that are affordable, comfortable and safe could be situated near to the hospital, to provide a supportive and reassuring environment before labour onset. Such homes have been associated with significant improvements in maternal and neonatal mortality in low income settings [77] and have been associated with positive maternal experiences [78]. However, women should never be compelled to attend such centres, as there is evidence that this can be traumatic for some, due to separation from family and friends, isolation, and loss of income if the woman cannot work [78-81]. The quality of the waiting home may also be a factor in their effectiveness in improving subsequent skilled birth attendance rates and outcomes [82].

\section{Research gaps, challenges and controversies}

These include the need to:

- Systematically examine the state of the art and research gaps in this area, from a clinical, behavioural, neurohormonal, psychological, social, and emotional perspective;

- Undertake primary science studies to address the identified gaps, taking account of the complex interconnectivity between the maternal and fetal dyad, and including pre-labour priming, the triggering mechanisms, and the consequences of these physiological process for the optimal postnatal adaptation of mother and newborn;

- Consider women's accounts of labour onset as a point of departure for basic science studies and for care provision in this area, including an assessment of temperature changes in late pregnancy;

- Explore the views and experiences of women in LMICs regarding the nature of labour onset, and what they should do once they believe they are in labour (research to date has focused primarily on HICs)

- Agree the criteria for labour onset as the basis for research studies that examine the impact of interventions on length of labour;

- Provide more clarity for women and health care providers around latent phase labour (in terms of both the definition and the support offered) in order to deliver care that is both woman centred and evidence-based.

- Examine the utility, affordability, acceptability and effectiveness of mobile technology solutions to agreeing labour onset between pregnant women, family and other stakeholders, and maternity care providers 
- Learn from the best in terms of provision of high quality, effective, acceptable maternity waiting homes

Challenge:

- To ensure that the development of any clinical tests in this area are balanced with the individual experiences and situations of women, so that the tests do not become the only assessment tool used to determine labour onset;

- If more precise measures of labour onset are established, to balance women's needs and right to health care provider advice and support with the risks of early hospital admission, to ensure that women (and their fetus) have access to appropriate care as and when they need it, without being exposed to the cascade of unnecessary interventions which is known to be associated with early admission to facilities.

- In settings where access to health care facilities is difficult, dangerous, and/or relatively expensive for women and families, to provide remote advice to women to ensure that they set off at the most opportune time in early labour and that facilities are able to support women who arrive before labour is established.

- To understand what the implications might be of routine labour induction in the absence of pathology, in the light of the neurophysiology of labour priming and initiation, and the consequences of these processes for maternal and newborn adaptation in the postnatal period.

\section{Summary of the content of the chapter}

A growing body of evidence suggests that the feto-maternal dyad is finely tuned to ensure that both the mother and the fetus are prepared, physically and neurohormonally, for labour onset, and, as a consequence, for optimal labour, birth, and early postnatal wellbeing. Practitioners working in maternity care need to understand the interrelationships between spontaneous labour onset and effective safe labour progress in healthy women and babies, and to respect these finely tuned processes. Maternal behaviours can be indicators of imminent labour onset. Respectful and appropriate attitudes of health care providers in response to maternal reports of signs of labour onset are essential to ensure that women are taken seriously; that they are supported in finding a place to wait for labour to establish that enables them to cope in the early stages, and that routine provision and standardisation does not misinterpret or interrupt the physiological process for individual women. This is particularly important when women have to travel far to access health care facilities, at high relative cost to them and their families. 
Increasing levels of routine labour induction at earlier and earlier gestations run the risk of interrupting these essential preparatory fetal and maternal processes, making it hard to initiate labour, and resulting in more pain and distress for mother and baby, with, as yet, unknown longer term consequences. Getting the professional and institutional response to labour onset right is likely to result in a higher chance of a smooth and successful labour and postpartum period that is safe for mother and baby, and results in a positive experience for them and their birth companions and professional attendants.

\section{Acknowledgements:}

This work did not receive any funding.

The authors acknowledge the support, in terms of time, provided by their institutions, and are grateful to the reviewers for feedback that has improved the manuscript.

\section{Conflict of interest:}

None 


\section{References}

[1] Berkeley C, Fairbairn JS, White C (Eds) Midwifery by ten teachers. London: Edward Arnold and Co; 1931, p258.

[2] Kamel RM. The onset of human parturition. Archives of Gynecology and Obstetrics, 2010;281(6): 975-982

* [3] Hanley GE, Munro S, Greyson D, Gross MM, Hundley V, Spiby H, et al. Diagnosing onset of labor: a systematic review of definitions in the research literature. BMC Pregnancy and Childbirth 2016;16:71

[4] Hundley V, Way S, Cheyne H, Janssen P, Gross M, Spiby H. Defining the latent phase of labour; is it important? Evidence Based Midwifery 2017;15(3):89-94.

[5] Abalos E, Oladapo OT, Chamillard M, Diaz V, Pasquale J, Bonet M, et al. Duration of spontaneous labour in 'low-risk' women with 'normal' perinatal outcomes: A systematic review. Eur J Obstet Gynecol Reprod Biol. 2018;223:123-132.

[6] World Health Organization. Definition of skilled health personnel providing care during childbirth: the 2018 joint statement by who, UNFPA, UNICEF, ICM, ICN, FIGO and ipa. Geneva, Switzerland: World Health Organization; 2018. Available from: https://apps.who.int/iris/bitstream/handle/10665/272818/WHO-RHR-18.14-eng.pdf?ua=1 [Accessed 10 February 2020]

[7] Thaddeus S, Maine D. Too far to walk: maternal mortality in context. Soc Sci Med 1994;38:10911110.

[8] Holmes P, Oppenheimer LW, Wen SW. The relationship between cervical dilatation at initial presentation in labour and subsequent intervention. British Journal of Obstetrics and Gynaecology 2001;108:1120-1124.

[9] Jackson DJ, Lang JM, Ecker J, Swartz WH, Heeren T. Impact of collaborative management and early admission in labour on method of delivery. Journal of Obstetric and Gynecologic and Neonatal Nursing 2003;32:147-57

[10] Klein MC, Kelly A, Kaczorowski J, Grzybowski S. The effect of family physician timing of maternal admission on procedures in labour and maternal and infant morbidity. Journal of Obstetrics and Gynaecology Canada 2004;26(7):641-645

[11] Cheng YW, Shaffer BL, Bryant AS, Caughey AB. Length of the first stage of labor and associated perinatal outcomes in nulliparous women. Journal of Obstetrics and Gynecology 2010;116(5):1127-1135.

[12] Lundgren I, Andren K, Nissen E, Berg M. Care seeking during the latent phase of labour Frequencies and birth outcomes in two delivery wards in Sweden. Sexual and Reproductive Healthcare 2013;4(4):141-146. 
[13] Janssen PA, Weissinger S. Women's perception of pre-hospital labour duration and obstetrical outcomes; a prospective cohort study. BMC Pregnancy and Childbirth 2014;14:182

[14] Chuma C, Kihunrwa A, Matovelo D, Mahendeka M. Labour management and obstetric outcomes among pregnant women admitted in latent phase compared to active phase of labour at Bugando medical Centre in Tanzania. BMC Pregnancy Childbirth 2014;14:68

* [15] Miller S, Abalos E, Chamillard M, Ciapponi A, Colaci D, Comandé D, et al. Beyond too little, too late and too much, too soon: a pathway towards evidence-based, respectful maternity care worldwide. Lancet. 2016 Sep 14. pii: S0140-6736(16)31472-6.

[16] WHO. Recommendations: induction of labour at or beyond term. Geneva, Switzerland: World Health Organization; 2018. Available from:

https://apps.who.int/iris/bitstream/handle/10665/277233/9789241550413-eng.pdf [Accessed 10 February 2020]

[17] Grobman WA, Rice MM, Reddy UM, Tita ATN, Silver RM, Mallet G, et al for the Eunice Kennedy Shriver National Institute of Child Health Development Maternal-Fetal Medicines Unit Network. Labor Induction versus Expectant Management in Low-Risk Nulliparous Women. New England Journal of Medicine 2018; 379;513-523.

[18] Hedegaard M, Lidegaard $\varnothing$, Skovlund CW, Morch LS, Hedegaard M. Reduction in stillbirths at term after new birth induction paradigm: results of a national intervention. BMJ Open 2014;4:e005785.

[19] Buckley SJ. Hormonal Physiology of Childbearing: Evidence and Implications for Women, Babies, and Maternity Care. Washington DC: Childbirth Connection Programs, National Partnership for Women \& Families 2015.

[20] Mendelson CR, Montalbano AP, Gao L. Fetal-to-maternal signaling in the timing of birth. J Steroid Biochem Mol Biol. 2017;170:19-27.

* [21] Vannuccini S, Bocchi C, Severi FM, Challis JR, Petraglia F. Endocrinology of human parturition. Ann Endocrinol. 2016;77(2):105-13.

[22] Fuchs AR, Fuchs F, Husslein P, Soloff MS. Oxytocin receptors in the human uterus during pregnancy and parturition. Am J Obstet Gynecol 1984;150(6):734-41.

* [23] Uvnäs-Moberg K, Ekström-Bergström A, Berg M, Buckley S, Pajalic Z, Hadjigeorgiou E, et al. Maternal plasma levels of oxytocin during physiological childbirth - a systematic review with implications for uterine contractions and central actions of oxytocin. BMC Pregnancy and Childbirth 2019;19:285.

[24] Levine LD, Valencia CM, Tolosa JE. Induction of labour. Full reference to be added by editors 
[25] Ravanos K, Dagklis T, Petousis S, Margioula-Siarkou C, Prapas Y, Prapas N. Factors implicated in the initiation of human parturition in term and preterm labor: a review. Gynecol Endocrinol. 2015;31(9):679-83.

[26] Lagercrantz H, Slotkin TA. The "stress" of being born. Sci Am. 1986 Apr;254(4):100-7.

* [27] Lagercrantz H. The good stress of being born. Acta Paediatr. 2016;105(12):1413-1416.

[28] Smithers LG, Searle AK, Chittleborough CR, Scheil W, Brinkman SA, Lynch JW. A whole-ofpopulation study of term and post-term gestational age at birth and children's development. BJOG. 2015 Sep;122(10):1303-11.

[29] Noble KG, Fifer WP, Rauh VA, Nomura Y, Andrews HF. Academic achievement varies with gestational age among children born at term. Pediatrics. 2012 Aug;130(2):e257-64. doi: 10.1542/peds.2011-2157.

[30] Gilbert CL. Endocrine regulation of periparturient behaviour in pigs. Reprod Suppl. 2001;58:2636.

[31] Hartmann C, Lidauer L, Aurich J, Aurich C, Nagel C. Detection of the time of foaling by accelerometer technique in horses (Equus caballus)-a pilot study. Reprod Domest Anim. 2018;53(6):1279-1286.

[32] Shaw EB, Houpt KA, Holmes DF. Body temperature and behaviour of mares during the last two weeks of pregnancy. Equine Vet J 1988;20(3):199-202.

[33] Johnson CA.Pregnancy management in the bitch. Theriogenology 2008;70(9):1412-7.

[34] Nabenishi H, Yamazaki A. Decrease in body surface temperature before parturition in ewes. J Reprod Dev 2017;63(2):185-190

* [35] Dixon L, Skinner J, Foureur M. Women's perspectives of the stages and phases of labour. Midwifery 2013;29:10-17.

* [36] Anderson M, Rutherford MD. Evidence of a nesting psychology during human pregnancy. Evolution and Human Behavior 2013;34(6):390-397

[37] Walsh DJ. 'Nesting' and 'Matrescence' as distinctive features of a free-standing birth centre in the UK. Midwifery 2006;22(3):228-39.

[38] Algers B, Uvnäs-Moberg K. Maternal behavior in pigs. Horm Behav. 2007;52(1):78-85.

[39] Cano-Ramírez H, Hoffman KL. Activation of cortical and striatal regions during the expression of a naturalistic compulsive-like behavior in the rabbit. Behav Brain Res 2018;1;351:168-177.

[40] Gross MM, Haunschild T, Stoexen T, Methner V, Guenter HH. Women's recognition of the spontaneous onset of labor. Birth 2003;30:267-271. 
* [41] Gross MM, Burian RA, Frömke C, Hecker H, Schippert C, Hillemanns P. Onset of labour: women's experiences and midwives' assessments in relation to first stage duration. Arch. Gynecol. Obstet 2009;280: 899-905.

[42] Friedman EA and Kroll BH. Computer analysis of labour progression. J. Obstet. Cynuec. Brit. Cwlth. 1969;7.6:1075-1079.

[43] Mclntosh T. The concept of early labour in the experience of maternity in twentieth century Britain. Midwifery 2013;29:3-9.

[44] Bovbjerg ML, Evenson KR, Bradley C, and Thorp JM. What Started Your Labor? Responses From Mothers in the Third Pregnancy, Infection, and Nutrition Study. J Perinat Educ. 2014;23(3):155-164.

[45] Declercq E., Sakala C., Corry M., \& Applebaum S. (2006). Listening to mothers II: Report of the second national U.S. survey of women's childbearing experiences. NewYork, USA: Childbirth Connection Available from: https://www.nationalpartnership.org/our-work/resources/healthcare/maternity/listening-to-mothers-ii-2006.pdf [Accessed 10 February 2020]

[46] Nordeng $\mathrm{H}$ and Havnen GC. Use of herbal drugs in pregnancy: a survey among 400 Norwegian women. Pharmacoepidemiol Drug Saf 2004;13(6):371-80.

[47] Zamawe C, King C, Jennings HM, Mandiwa C, Fottrell E. (2018) Effectiveness and safety of herbal medicines for induction of labour: a systematic review and meta-analysis. BMJ Open 2018;17;8(10):e022499.

[48] Mawoza T, Nhachi C and Magwali T. Prevalence of Traditional Medicine Use during Pregnancy, at Labour and for Postpartum Care in a Rural Area in Zimbabwe. Clin Mother Child Health. 2019; 16(2): 321.

[49] Hall HG, McKenna LG, Griffiths DL. Complementary and alternative medicine for induction of labour. Women Birth 2012;25(3):142-8.

[50] Dugoua JJ, Perri D, Seely D, Mills E, Koren G. Safety and efficacy of blue cohosh (Caulophyllum thalictroides) during pregnancy and lactation. Can J Clin Pharmacol 2008;15(1):e66-73.

[51] James PB, Bah AJ, Tommy MS, Wardle J, Steel A. Herbal medicines use during pregnancy in Sierra Leone: An exploratory cross-sectional study. Women Birth 2018;31(5):e302-e309.

[52] Peprah P, Agyemang-Duah W, Arthur-Holmes F, Budu HI, Abalo EM, Okwei R, et al. 'We are nothing without herbs': a story of herbal remedies use during pregnancy in rural Ghana. BMC Complement Altern Med 2019;15;19(1):65.

[53] Kamatenesi-Mugisha M1, Oryem-Origa H. Medicinal plants used to induce labour during childbirth in western Uganda. J Ethnopharmacol 2007;109(1):1-9. 
[54] Faron G, Balepa L, Parra J, Fils JF, Gucciardo L. The fetal fibronectin test: 25 years after its development, what is the evidence regarding its clinical utility? A systematic review and metaanalysis. J Matern Fetal Neonatal Med 2018;9:1-31.

[55] Phillippe M. Cell-Free Fetal DNA, Telomeres, and the Spontaneous Onset of Parturition. Reprod Sci 2015;22(10):1186-201.

* [56] Cheyne H, Dowding D, Hundley V. Making the diagnosis of labour: midwives' diagnostic judgement and management decisions. J Adv Nurs 2006;52:625-635.

[57] Chodzaza E, Haycock-Stuart E, Holloway A, and Mander R. Cue acquisition: A feature of Malawian midwives decision making process to support normality during the first stage of labour. Midwifery 2018;58:56-63.

[58] Vik ES, Haukeland GT, and Dahl B. Women's experiences with giving birth before arrival. Midwifery 2016;42:1-15.

[59] Nyman V, Downe S, and Berg M. Waiting for permission to enter the labour ward world: First time parents' experiences of the first encounter on a labour ward. Sexual \& Reproductive Healthcare 2011;2:129-134

[60] Barnett C, Hundley V, Cheyne H and Kane F. "Not in labour" - the impact of being sent home in the latent phase. British Journal of Midwifery 2008;16(3):144-153.

[61] Cheyne $\mathrm{H}$ and Hundley V. Has labor started? A judgment made in uncertainty. Birth 2009;36(4):336-337

[62] Lauzon L and Hodnett ED. Labour assessment programs to delay admission to labour wards. Cochrane Database of Systematic Reviews 2001, Issue 3. Art. No.: CD000936. DOI: 10.1002/14651858.CD000936.(updated 2009)

[63] Carlsson IM, Ziegert K, Sahlberg-Blom E, and Nissen E. Maintaining power: Women's experiences from labour onset before admittance to maternity ward. Midwifery 2012;28:8692.

[64] Eri TS, Bondas T, Gross MM, Janssen P, Green JM. A balancing act in an unknown territory: a metasynthesis of first-time mothers' experiences in early labour. Midwifery 2015;31(3):e5867.

[65] Beebe KR and Humphreys J. Expectations, perceptions, and management of labor in nulliparas prior to hospitalization. J Midwifery Women's Health 2006;51:347-53.

[66] Low LK and Moffat A. Every labor is unique, but "call when your contractions are 3 minutes apart". MCN 2006; 31:307-12. 
[67] Nolan M, Smith J. Women's experiences of following advice to stay at home in early labour. British Journal of Midwifery 2010;8(5): 286-291.

[68] Simkin P, Stewart M, Shearer B, Glantz C, Rooks JP, Lyerly AD, Chalmers B and Keirse MJNC. The Language of Birth. Birth 2012;39:2:156-164.

[69] Bohren MA, Tuncalp $O$ and Miller S. Transforming intrapartum care: Respectful maternity care. Full reference to be added by editors

[70] Shallow HED, Deery R, and Kirkham M. Exploring midwives' interactions with mothers when labour begins: A study using participatory action research. Midwifery 2018;58:64-70.

[71] Spiby H, Green JMG, Renfrew MJ, Crawshaw S, Stewart P, Lishman J, et al. Improving care at the primary/secondary interface: a trial of community-based support in early labour. The ELSA trial. Final report submitted to the National Co-ordinating Centre for NIHR Service Delivery and Organisation (NCCSDO), Nov 2008.HMSO: London. Available from:http://www.netscc.ac.uk/hsdr/files/project/SDO FR 08-1304-040 V01.pdf [Accessed 10 February 2020]

[72] Spiby H, Walsh D, Green J, Crompton A, Bugg G. Midwives' beliefs and concerns about telephone conversations with women in early labour. Midwifery 2014; 30(9):1036-42

[73] Bailey CM, Newton JM, Hall HG. Telephone triage and midwifery: A scoping review. Women Birth 2018;31(5):414-421.

[74] Watson AHA, Sabumei G, Mola G, Ledema R. Maternal Health Phone Line: Saving Women in Papua New Guinea J. Pers. Med. 2015, 5(2), 120-139.

* [75] Sondaal SFV, Browne JL, Amoakoh-Coleman M, Borgstein A, Miltenburg AS, Verwijs M, et al. Assessing the Effect of mHealth Interventions in Improving Maternal and Neonatal Care in Low- and Middle-Income Countries: A Systematic Review. PLOS One 2016; 11(5): e0154664.

[76] Hampshire Hospitals NHS Foundation Trust (HHFT) and South Central Ambulance Service (SCAS). 24 hour labour line. NICE guidance. National Institute for Health and Care Excellence: London. Available from: https://www.nice.org.uk/sharedlearning/24-hour-labour-line [Accessed 10 February 2020]

[77] Dadi TL, Bekele BB, Kasaye HK, Nigussie T. Role of maternity waiting homes in the reduction of maternal death and stillbirth in developing countries and its contribution for maternal death reduction in Ethiopia: a systematic review and meta-analysis. BMC Health Serv Res 2018;18(1):748.

[78] Lori JR, Munro-Kramer ML, Shifman J, Amarah PNM, Williams G. Patient Satisfaction With Maternity Waiting Homes in Liberia: A Case Study During the Ebola Outbreak. J Midwifery Womens Health 2017;62(2):163-171. 
[79] Lawford KM, Giles AR, Bourgeault IL. Canada's evacuation policy for pregnant First Nations women: Resignation, resilience, and resistance. Women Birth 2018;31(6):479-488

[80] Vermeiden T, Schiffer R, Langhorst J, Klappe N, Asera W, Getnet G, et al. Facilitators for maternity waiting home utilisation at Attat Hospital: a mixed-methods study based on 45 years of experience. Trop Med Int Health 2018;23(12):1332-1341.

[81] Kurji J, Gebretsadik LA, Wordofa MA, Sudhakar M, Asefa Y, Kiros G, et al. Factors associated with maternity waiting home use among women in Jimma Zone, Ethiopia: a multilevel crosssectional analysis. 2019;28;9(8):e028210.

[82] Henry EG, Semrau K, Hamer DH, Vian T, Nambao M, Mataka K, Scott NA. The influence of quality maternity waiting homes on utilization of facilities for delivery in rural Zambia. Reprod Health 2017;14(1):68. 
Figure 1. Maternal hormonal/physiological changes from pregnancy to postpartum.

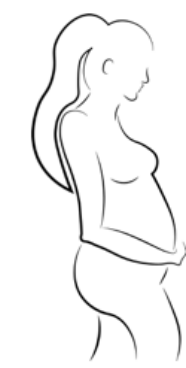

Pregnancy

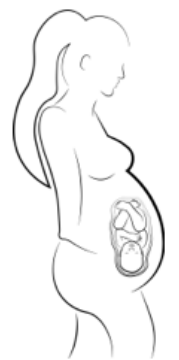

Late pregnancy

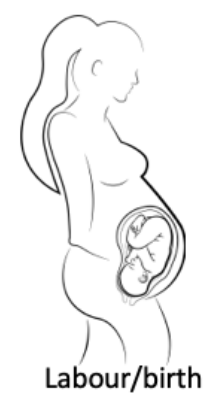

\section{Phase 2}

Stimulation

个 Oxytocin

$\uparrow$ Prostaglandins

$\uparrow \mathrm{CRH}$

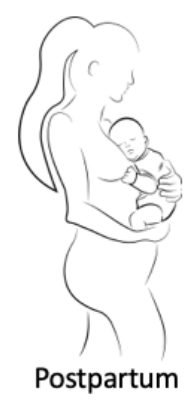

Phase 3

Involution

$\downarrow$ Progesterone

$\downarrow$ Estrogen

个 Oxytocin (breastfeeding)

$\uparrow \mathrm{CRH}$ (Corticotropic

$\uparrow$ Estrogen

$\uparrow$ Oxytocin receptors

$\uparrow$ Gap junctions

$\uparrow$ Inflammation

$\uparrow$ Prostaglandins

$\uparrow$ Cervical ripening

$\uparrow \mathrm{CRH}$

Original figure produced for this article and reproduced with permission @ Gary Mills Art 
Figure 2: Effects of the fetal catecholamine surge on the fetus/newborn

IMPROVES BREATHING

INCREASES LUNG SURFACTANT

INCREASES LUNG-LIQUID ABSORPTION

IMPROVES LUNG COMPLIANCE

DILATES BRONCHIOLES

PROTECTS HEART AND BRAIN

INCREASES BLOOD FLOW TO VITAL ORGANS

MOBILIZES FUEL

BREAKS DOWN NORMAL FAT INTO FATTY

ACIDS

BREAKS DOWN GLYCOGEN (IN LIVER) TO

GLUCOSE

STIMULATES NEW PRODUCTION OF

GLUCOSE

BY LIVER

FACILITATES BONDING

DILATES PUPILS

APPEARS TO INCREASE ALERTNESS

INITIATES THERMOREGULATION

BURNS BROWN FAT

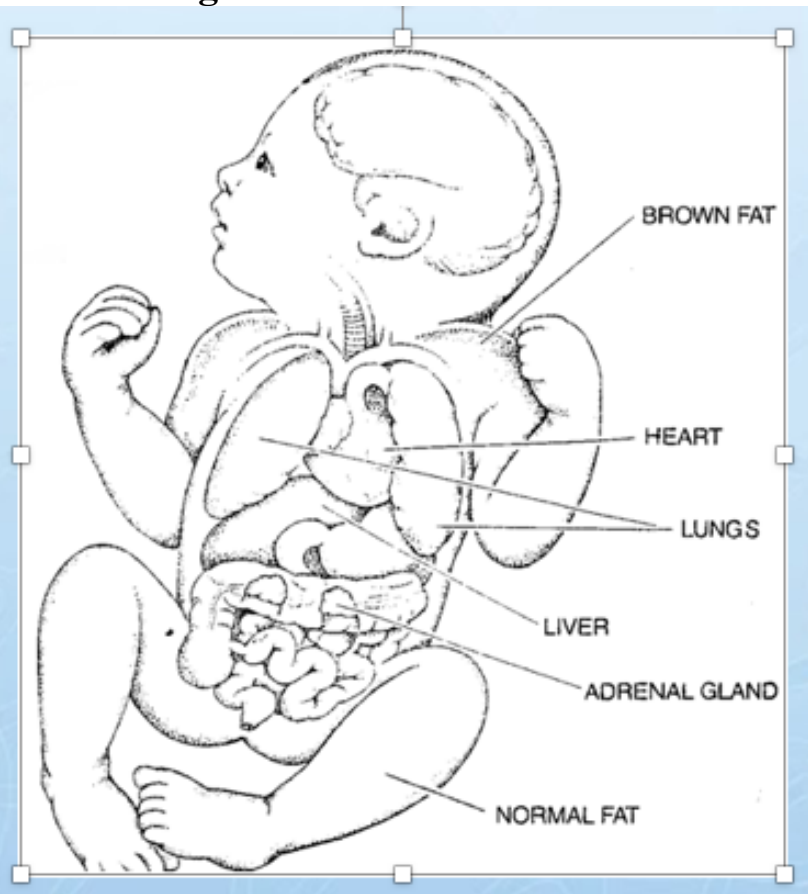

Lagercrantz, H. and T. A. Slotkin (1986). "The "stress" of being born." Sci Am 254 (4): 100-7 Used with permission..

Figure reproduced with permission [22] 